\title{
Influence of Screw Access Channel on All Ceramic Cement-Retained Implant Supported Posterior Crowns
}

\author{
Amr El-Sayed Khalifa ${ }^{1}$, Dawlat Mostafa ${ }^{2}$, Mohamed Moataz M. Khamis ${ }^{3}$ \\ ${ }^{1}$ BDS, MS, Alexandria University, Faculty of Dentistry, Alex, Egypt \\ ${ }^{2}$ Lecturer of Dental Biomaterial, Alexandria University Faculty of Dentistry, Alex, Egypt \\ ${ }^{3}$ Professor of Prosthodontics, Alexandria University Faculty of Dentistry, Alex, Egypt
}

\begin{abstract}
Statement of the problem: The presence of a screw access channel on the occlusal surface of implant-supported all ceramic crowns may reduce the fracture resistance of the restoration. Purpose: Evaluate the effect of screw access channel on the fracture resistance, fracture pattern and defects at the fracture origin after subjecting to vertical compression load on cement retained implant posterior crowns. Material and methods: Four parallel groups, eight specimens each, were examined in this study. The specimens were subjected to thermal cycling corresponding to one year clinical service, and then were subjected to fracture resistance testing \& fractographic analysis. The specimens were grouped as follows, Group A: restorationswere constructed with lithium disilicate glass ceramic with no occlusal access channel. Group B: restorations were constructed with lithium disilicate glassceramic with screw access channel at the center of their occlusal surfaces. Group C: restorationswere constructed with zirconium oxide ceramic with no occlusal access channel. Group D: restorationswere constructed with zirconium oxide ceramic with screw access channel at the center of their occlusal surfaces. Results: The highest mean $(S D)$ fracture resistance was $6193.7 \pm 1627.2 \mathrm{~N}$ recorded in group $C$ followed by $3282.59 \pm 1006.07 \mathrm{~N}$ recordedin group $D$, then $2528.44 \pm 453.54 \mathrm{~N}$ recorded in group $A$ and the lowest mean fracture resistance was $2458.75 \pm 230.28 \mathrm{~N}$ recorded in group $B$. Conclusion: occlusal screw access channel had no significant effect on lithium disilicate glass ceramic and had a significant effect on zirconium oxide ceramics.
\end{abstract}

Keywords: screw access channel, cement-retained implant supported restoration, fracture resistance, fractographic analysis

\section{Introduction}

Implant-supported crowns offer a viable and popular option for replacing missing teeth without the need to remove tooth structure, as with conventional fixed partial dental prostheses. They are also generally preferred as a treatment option for missing teeth over removable partial dentures. [1]The successful osseointegration and long-term survival of oral implants depends on several biomechanical factors. The selection of appropriate implant position, prosthesis design, biocompatibility and mechanical and physical properties of the materials is critical for the longevity, stability and proper function of the implant prosthesis. [2]

Stegaroiu et al [3]assessed stress distribution in bone, implant, and abutment when gold alloy, porcelain, or resin (acrylic or composite) was used for a 3-unit prosthesis, and found that Similar stress was found in bone and the implant abutment units in the gold alloy and porcelain prosthesis models, the use of acrylic or composite resin instead of porcelain or gold may increase stress in the implant and the abutment, in the absence of a metal framework.

While Ismail et al [4] analyzed the influence of the occlusal material (porcelain, precious and non-precious alloy, acrylic or composite resin) on the stress in bone and implant, and they reported similar results for all the investigated materials.
Initially, implant-supported prostheses were exclusively retained by screws and studies have confirmed their success, particularly in fully edentulous patients. However, with the development of new implant systems and new rehabilitation techniques, cement-retained prostheses have become a popular treatment option, mainly in treatments with single and fixed partial prostheses. Currently, cement-retained prostheses are frequently used with a high level of success. [5]

Screw retention in implant-supported prosthesis was developed in response to the need for retrievability even though occlusion and esthetics were sacrificed. There is almost no tolerance for error in the fabrication of the screw retained prosthesis because a direct metal-to-metal connection exists. $[6,7]$

The main drawbacks of cement-retained restorations are difficult retrievability and retention of excess cement, especially when the restoration margins are placed subgingivally or the implants are deeply placed. Diligence in cement removal at time of cementation is critical. The presence of cement residue can be detrimental to periimplant health. Residue can cause peri-implant inflammation associated with swelling, soreness, deeper probing depths, bleeding and/or exudation on probing, with radiographic evidence of peri-implant bone loss, and may eventually result in implant loss.[8]

In 2014,Silva et al [5]compare the preload maintenance, stresses, and displacements of prosthetic components of 


\section{International Journal of Science and Research (IJSR) \\ ISSN (Online): 2319-7064 \\ Index Copernicus Value (2013): 6.14 | Impact Factor (2015): 6.391}

screw- and cement-retained implant-supported prostheses by using the finite element method in a nonlinear analysis and it was foundthat screw retained implant-supported prostheses showed a higher biomechanical risk of failure than the cement-retained implant-supported prostheses.

Factors influencing success of cement-retained versus screw -retained implant restoration that cement retained crowns have the advantage of being more passively attached to the implant, which may prevent or reduce the concentration of stresses when there is slight misalignment among the crown, implant, and adjacent teeth. The slight cement space present between the crown and abutment offers a degree of compensation (stress relief), which is an advantage. Another advantage of Cement retained crowns is the easier laboratory fabrication procedures resulting in reduced laboratory costs compared to those of tooth-supported crowns. [9]

One short coming of cemented crowns is the difficulty with the removal of the excess cement. Another significant shortcoming of the cemented reconstructions is that, in case of problems, they are difficult or impossible to remove without destruction, for example, in cases of technical complications. [10]

It may be necessary to retrieve the restoration and access the abutment screw, and these tasks can be challenging, so predictable retrievability of cement-retained prostheses has been a clinical concern.[11]

Interim luting cements have been recommended to allow cement-retained restorations to be removed from the abutment without harming the restoration[11] Interim cement may be preferred because of easier retrievability of the restoration and excess cement removal despite low retention and high solubility [12] but an increase in the demand for stronger retention, definite types of cement have also been widely used. [13]

In 2011 ,Schweitzer et al[14]modified a technique that describes an implant restoration design which will allow predictable removal of cement-retained implant-supported prostheses, by involvinga lingual retrieval slot mechanism.

Several authors have described techniques to facilitate making the screw access hole, including photographs containing the location of the screw channel[15] and radiographs showing the implant axis,[16] and provide information regarding the screw position,[17] Staining the occlusal surface of the restoration or using a vacuum formed template are useful techniques for indicating the starting point for drilling.[11]

An alternative design, known as "the combination implant crown," has been suggested by Rajan and Gunaseelan[18].For this design, the definitive crown is cemented to theimplant abutment extraorally. Excess cement is easily removed extraorally, and the cemented assembly can be screwed onto the implant through an access screw channel in the restoration, which is later closed bycomposite resin.
By incorporating both the simplicity of cemented-retained prostheses on the one hand and the retrievability of screwretained prostheses on the other hand, provided that this process does not reduce the biomechanical quality, creates an important option in the fabrication of the implant prostheses.[19]

In 2010, Al Omari et al[20] had compared the porcelain fracture resistance between screw-retained, cement-retained, and combined screw- and cement-retained metal-ceramic implant-supported posterior single crowns and it was stated that, The cement-retained restorations showed significantly higher mean fracture loads than the restorations having screw-access openings in their occlusal surface. Also had investigated the effect of offsetting the occlusal screwaccess opening on porcelain fracture resistance of screwretained and cement-retained Metal-ceramic implantsupported posterior single crowns and it was stated that the position of the screw-access hole within the occlusal surface did not significantly affect the porcelain fracture resistance.

In 2011, shadid et al [21] had evaluated the effect of occlusal screw access hole on the fracture resistance of cementretained metal ceramic implant supported posterior crowns and it was stated that the screw access hole on the occlusal surface lower the fracture resistance of the veneering porcelain.

While nowadays, ceramics are widely used in dentistry due to their ability to mimic the optical characteristics of enamel and dentin and their biocompatibility and chemical durability. [22] All-ceramic restorations have become more popular in restorative treatments. [23]

In this study, screw access channel was fabricated during milling of monolithic crowns either lithium disilicate reinforced glass ceramics or zirconium oxide ceramics, then evaluate the effect of creating a screw access channel in an all ceramic cement retained posterior implant restoration on fracture resistance after subjecting it to vertical compression load. The fracture pattern and defects at the fracture origin will also be evaluated.

\section{Material and Methods}

This study was a parallel, controlled, in vitro study in which the fracture resistance of four parallel groups was examined. With the aid of an iso-parallelometer milling machine (Cruise 440,Silfradent) Four internal hexagon implants with a $3.7 \mathrm{~mm}$ diameter and $10 \mathrm{~mm}$ length (Dentis CO., South Korea) with a straight abutment were used.Each one was embedded in a special specimen holder, in a clear auto-polymerizing polymethyl methacrylate acrylic resinaligned at $90^{\circ}$ to the horizontal plane.

Firstly, the openings on the top of the implant abutment top were blocked using sticky wax, then the abutments received scanning anti-glare spray (Helling -3D laser spray) to create an opaque surface needed for scanning by creating a 3-dimensional virtual model to create a computer-aided designed/computer-aided manufactured (CAD/CAM) model for a ceramic crown representing the mandibular right first molar.The dimensions of the crowns in all groups (A, B, C, 


\section{International Journal of Science and Research (IJSR) \\ ISSN (Online): 2319-7064 \\ Index Copernicus Value (2013): 6.14 | Impact Factor (2015): 6.391}

D) were with a standardized anatomical occlusal surface , the bucco-lingual dimensions were $11 \mathrm{~mm}$, the mesio-distal dimensions were $12.0 \mathrm{~mm}$ and the occluso-cervical dimensions were in range of $8.5 \mathrm{~mm}$.

The screw access holes in group (B, D) were standard in dimensions in the center of the occlusal surface of the restorations with diameter of $3 \mathrm{~mm}$ corresponding to the diameter of the opening on the top of the implant abutment.

Thefollowing 2 types of ceramic crowns were fabricated withand without occlusal screw-access channels: monolithiclithium disilicate crowns group A \&group B (IPS e.max CAD; Ivoclar Vivadent AG), monolithic zirconia crowns group C \&group D (Katana Zircon blocks, Kuraray Medical Inc. and Noritake Dental Supply Co. Japan).

For group A \& BThe sprayed abutment was scanned using an optical 3-dimensional intraoral camera (CEREC Omni Cam, Sirona Dental System)4.3.1 Software version was used to design the restoration according to the previous crown standard parameters, Regarding to the restorations with occlusal access hole, the same as all the previous steps, except during designing, the restorations with occlusal access hole were fabricated with diameter $3 \mathrm{~mm}$ corresponding to the hole at the top of the scanned abutment. CEREC MCXL(Sirona Dental System) was used to mill the restorations, After recovering the precrystallized crowns from the milling chamber, the crowns were trial fitted to the implant abutment to ensure complete seating. An auxiliary firing paste(Object fix putty, Ivoclar Vivadent)was applied to the fitting surface of each restoration before crystallization which helps in stabilization of the restorations, and then all the restorations were placed on specific pins(IPS e.max CAD crystallization pins, Ivoclar Vivadent)according to the manufacturers' instructions, The crowns milled were crystallized in a ceramic furnace(Programat P300, Ivoclar Vivadent) for 30 minutes at a final temperature of $850^{\circ} \mathrm{C}$ under vacuumThen the crowns were allowed to cool at room temperature, then cleaned and dried from any adhering residue with ultrasonic in a water bath according to the manufacturers' instructions.

For group C\&DThe sprayed abutment was scanned using an optical 3-dimensional extraoral scanner (Activity 880 Smart Optics Extra oral scanner)ZirkonZahn Software version was used to design the restoration while Roland DWX-50 (Roland DGA, California)was used to mill the crowns, then all crowns were sintered in a special sintering high temperature furnace (Mihim-Vogt company,Stutensee-Blankenloch) at $1500^{\circ} \mathrm{C}$ for 12 hours.

Preparation for cementation of group A\&B: The inner surface of the crowns was etched with $5 \%$ hydrofluoric acid (IPS Ceramic Refill, IvoclarVivadent)using disposable brush for 20 seconds, then the ceramic etching gel was rinsed off from the crowns under running water as manufacturing instructions, Then the internal surface of the restoration was dried with clean, dry air from a dental syringe, and Silane coupling agent(Calibra ${ }^{\circ}$, dentsply) was applied to the etched portion of a ceramic restoration for 20 seconds using supplied needle tip which was attached to end of the Silane Coupler syringe. Gently pressure was applied to syringe plunger. Then directly the silane coupling agent was applied to the etched, clean internal surface of the restoration.

While Preparation for cementation of group C \& Dwas done bysandblasting (Modular Sandblasting Machine, silfradent, Italy) by $50 \mathrm{um}$ alumina at 30 psiand at a distance of $2 \mathrm{~cm}$.

Cementation of all the crowns was performed with a dual cure resin cement(3M ESPE 3M Center United States)according to the manufacturer's instructions, Then the crowns were cemented onto the abutments with the aid of a specific device with which a cementing load of 1 kilogram for 3 minutes was standardized.Excess cement was removed with a micro brush, followed by photo activation by light-emitting diode (LED) for 60 seconds on each side, with more than 1,000 milliwats per square centimeter intensity. Then a cotton pellets was inserted into the abutment to protect the head of the screw. Then the access hole was filled by composite material followed by photo activation by light-emitting diode (LED) for 20 seconds per increment, with more than 1,000 milliwats per square centimeter intensity and then the composite was polished.

After securing the abutments to their corresponding implants and cementing the crowns to their abutments, all the specimens were thermo-cycled (Custom thermo-cycling machine at department of dental biomaterials, faculty of dentistry, university of Alexandria) All the specimens were subjected to 2000 cycles of thermal cycling in a custommade thermal cycling machine that correspond to one year of physiological aging in the oral cavity, Each 60-secondslong cycle consisted of 15 second of time in each baths of 5 $\mathrm{C}^{\circ}$ and $55 \mathrm{C}^{\circ}$ as ISO 11405 recommendations (International Standards Organization, 1994), with 2 transport times of 15 seconds each between the 2 baths.

\section{Fracture Resistance Test}

All the samples were secured in the holding device of a universal loading machine at science and technology center at Borg El Arab, Alexandria(Shimadzu Autograph AG-IS 100KN, Japan) to perform compressive loading tests under static condition until the fracture of the specimens, in order to assess the maximum load resistance and the fracture mechanisms. A controlled load at a crosshead speed of $1 \mathrm{~mm} / \mathrm{min}$ was applied by means of a stainless steel rod with a spherical tip of $8 \mathrm{~mm}$ of diameter, in order to simulate an occlusal load. The spherical tip was left in contact with the buccal and lingual cuspal inclines and the applied force was parallel to the longitudinal axis of the specimens, All samples were loaded from 0 Newtons (N) until fracture. The load fracture and the work at maximum load were recorded in Newtons by means of a computer connected to the loading machine, using specific measurement software.

\section{Fractographic Analysis}

The fractured specimens were metalized with gold, using a sputter coater (JEOL JFC-1100E ion, Tokyo) at 


\section{International Journal of Science and Research (IJSR) \\ ISSN (Online): 2319-7064 \\ Index Copernicus Value (2013): 6.14 | Impact Factor (2015): 6.391}

faculty of Science, University Of Alexandria and observed with a scanning electron microscope (JEOLJSM-5300, Tokyo) at Faculty of science University of Alexandria.

The analysis of the Fracture modes was performed using $\mathrm{x} 50$ magnification and for higher definition of specific key crack features in the selected areas of interest x 200 .

\section{Statistical Analysis}

Data were presented as mean and standard deviation (SD) values. Data were explored for normality using Kolmogorov-Smirnov and Shapiro-Wilk tests test for Normal distribution. Independent t-test was used to study the effect of screw access hole design and materials of construction on the Fracture resistance $(\mathrm{N})$ within each group.

\section{Results}

Fracture resistance test:

The mean fracture resistances in Newton are presented in table (1) and graphically in graph (1).

The highest mean fracture resistance was $6193.7 \pm 1627.2 \mathrm{~N}$ recorded in group $\mathrm{C}$ followed by $3282.59 \pm 1006.07 \mathrm{~N}$ recorded in group $\mathrm{D}$, then $2528.44 \pm 453.54 \mathrm{~N}$ recorded in group $\mathrm{A}$ and the lowest mean fracture resistance was $2458.75 \pm 230.28 \mathrm{~N}$ recorded in group B.

There was no significant difference between group A and group $B$ with $p=0.704$, while there was a significant difference between group $\mathrm{C}$ and group $\mathrm{D}$ with $\mathrm{p}=0.001$.

Table 1: Mean and standard deviation (SD) of mean Fracture resistance in Newton within different material of construction

\begin{tabular}{|c|c|c|c|}
\hline & Mean & SD & p-value \\
\hline Group A & 2528.44 & 453.54 & $0.704 \mathrm{NS}$ \\
\hline Group B & 2458.75 & 230.28 & \\
\hline Group C & 6193.70 & 1627.20 & $0.001 *$ \\
\hline Group D & 3282.59 & 1006.07 & \\
\hline
\end{tabular}

*=Significant, $N S=$ Non-significant

Fracture resistance $(\mathrm{N})$

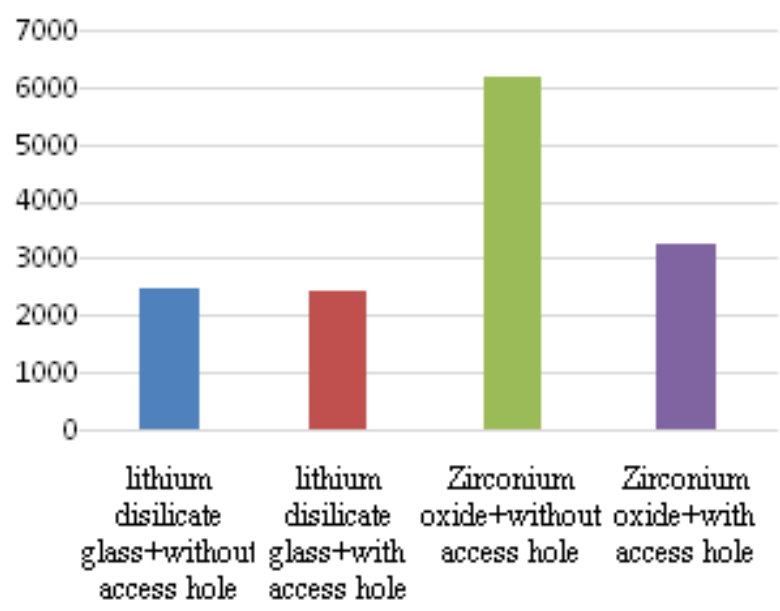

Graph 1: Histogram showing the mean Fracture resistance (N) for different groups
One Way ANOVA used to compare between the mean forces in Newton $(\mathrm{N})$ required for fracture resistance of the four tested groups followed by Tukey's post-hoc test that was used for pair-wise comparison between the means when ANOVA test is significant, table (2).

On the comparison between the mean fracture resistances of the four tested groups, only group $\mathrm{C}$ showed significant difference with the other three groups, while there was no any significant difference among the three other groups

Table 2: Mean and standard deviation (SD) of mean Fracture resistance $(\mathrm{N})$ for different groups

\begin{tabular}{|c|c|c|c|c|}
\hline & \multicolumn{2}{|c|}{ Fracture resistance (N) } & Rank & p-value \\
\cline { 2 - 4 } & Mean & SD & & \\
\hline Group A & 2528.44 & 453.54 & b & \multirow{2}{*}{$\leq 0.001^{*}$} \\
\hline Group B & 2458.75 & 230.28 & b & \\
\hline Group C & 6193.70 & 1627.20 & $\mathrm{a}$ & \\
\hline Group D & 3282.59 & 1006.07 & $\mathrm{~b}$ & \\
\hline
\end{tabular}

Means with the same letter within each row are not significantly different at $p=0.05$.

*=Significant

\section{Fractographic Analysis}

The SEM observations revealed that the fracture patterns of both failed lithium disilicate tested specimens and zirconium oxide tested specimens were different.

Lithium disilicate specimens showed that the origin of the fracture started at the occlusal loading point which was marked by black arrows then the direction of crack propagation was revealed where the crack extension penetrated deep along the mesio-distal direction, and eventually resulted in bulk fracture, which was marked by white arrows and was confirmed by the twist hackles and the concave orientation of the arrest lines, where the fracture path that propagated in the mesio-distal plane separated the crown into two pieces.fig (1), No features were determined of the source of fracture originate from or around the screw access hole in the most of group B specimens.

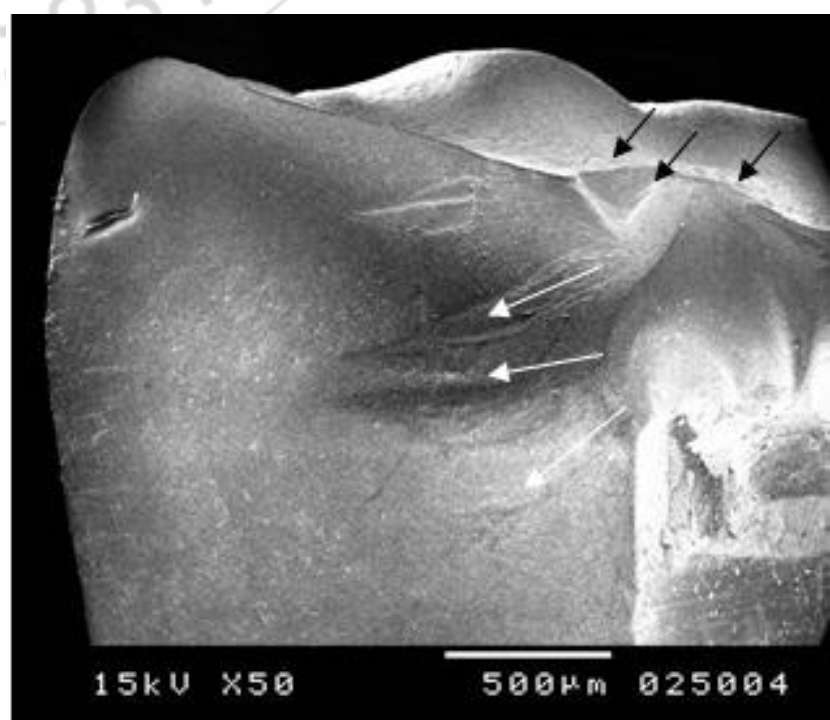

Figure 1: SEM of lithium disilicate groups showing origin of the fracture black arrows\& direction of crack propagation white arrows 


\section{International Journal of Science and Research (IJSR) \\ ISSN (Online): 2319-7064}

Index Copernicus Value (2013): 6.14 | Impact Factor (2015): 6.391

On the other hand, Zirconium oxide groups, most specimens showed a fracture path that propagated, both the mesio-distal and buccal fissures, consequently the crown failed into three pieces. In some instances more than three pieces were observed in a few crowns, because the occlusal fissure underneath the loading piston broke into multiple pieces.

Zirconium oxide specimens without an access hole The origin of the fracture started at the occlusal loading point which was marked by black arrows. The cracked surface that forms during the initial propagation has a smooth area, which is a Characteristic pattern appropriately termed the mirror region which is surrounded by a black circle.

The direction of crack propagation was toward the cervical portion of the restoration along the axial wall of the fitting surface downward, and was confirmed by the concave orientation of the arrest lines was an indication of the direction of the crack, which was marked by white arrows.As the crack advances, it becomes more unstable, creating a hollow surface known as mist, which is surrounded by a white circle. This instability eventually causes the crack to branch out, thereby producing the rough hackle region. The hackle region is composed of a set of striations of lines that radiate away from the crack source toward the axial wall of the fitting surface which are resembled by the white arrows, fig ( )

While zirconium oxide specimens with an access holeWhile the direction of the crack propagation emanating from the mirror toward the axial wall of the screw access channel through radiating hackles which are marked by white arrows, fig ( )

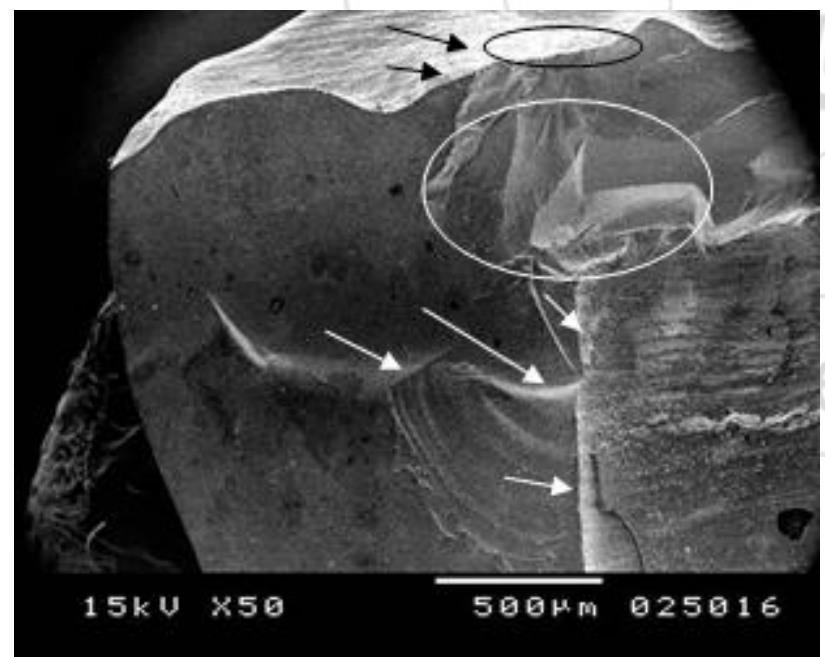

Figure 2: SEM of group $\mathrm{C}$ showing the origin of fracture marked by black arrows, mirror marked by black circle, mist and irregular hackles marked by white circles and DCP marked by white arrows along fitting surface.

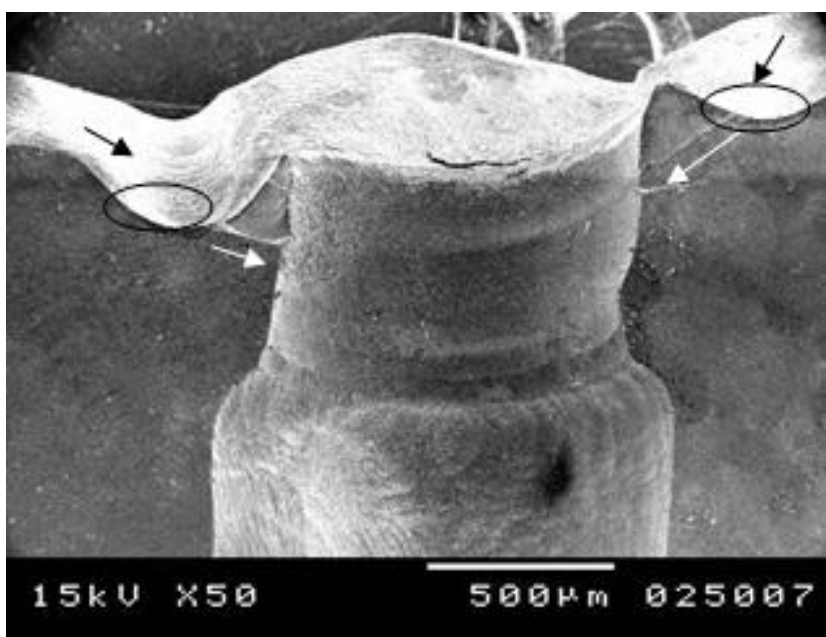

Figure 3: SEM of group D showing the origin of fracture marked by black arrows, mirror marked by black circle, and DCP marked by white arrows along the screw access hole

\section{Discussion}

The present study compared the fracture resistance of cement retained implant supported all-ceramic posterior crowns with screw-access channels, referred to as combinationimplant crown,[24]with that of cement retained all-ceramic crowns without an access channel.

Cement -retained implant supported posterior crowns with screw access channel offer the advantage of retrievability [13] combined with better tissue tolerance.

The fracture strength of ceramic restorations has been studied previously, however the effect of a channel specifically designed for retrievability of cemented retained implant supported ceramic crowns on fracture strength has not been studied.

This study was designed with two commonly used ceramic materials to test the fracture resistance of each individual group with and without screw access channels.

Many authors believed that the screw access channel affect the fracture resistance of metal ceramic crowns[20], due to the presence of the screw access hole at the occlusal surface which often causes biomechanical complications and fracture of the veneering porcelain which compromise the long term success of the restoration, it was identified that the occurrence of these failures was due to the difference of coefficient of thermal expansion (CTE) which is higher in metal than in the veneering porcelain.

Thereby the metal framework is subjected to a more evident shrinkage than that of veneering porcelain toward the center of the bulk.

Based on the previous, in screw retained restorations, the occlusal screw cuts the continuity of the veneering porcelain which causes local failures of the metal ceramic bond and the detachment of the veneering porcelain.

However, Torrado et al[25]reported that screw-retained, implant-supported metal ceramic crowns revealed 


\section{International Journal of Science and Research (IJSR) \\ ISSN (Online): 2319-7064 \\ Index Copernicus Value (2013): 6.14 | Impact Factor (2015): 6.391}

significantly lower fracture resistance than cement retained metal ceramic crowns. Zarone et al[26]reported no significant differences in fracture resistance between implant-supported screw and cement-retained metal ceramic restorations

Karl et al[27]compared the effects of dynamic loading between screw-retained and cement-retained implantsupported partial fixed dental prostheses and reported more chipping fractures with screw-retained implant-supported partial fixed dental prostheses.

In this study, the mean failure loads for all the examined specimens were well above the masticatory forces normally exerted (847 N for men and $597 \mathrm{~N}$ For women) within the posterior molar region of the mouth. [28]

Regarding to the results of the fracture resistance of the 4 tested groups, it was found that group $\mathrm{C}$ and group D show high fracture resistance than group A and group B, which can be related to the high crystalline content of the zirconia based material that resulted in better mechanical propertieswhile the lithium disilicate groups has glassy matrix reinforced with lithium disilicate crystals.

The influence of the screw access channel on the zirconia groups was obvious, as there was a significant difference between the fracture resistance of the group $\mathrm{C}$ and group $\mathrm{D}$.

it was identified that, the shrinkage occur toward the center of the mass of the bulk where the screw access hole was fabricated leading to disruption of the structural continuity of the zirconia crowns, So the screw access hole at the center of the occlusal surface of group D significantly decrease the fracture resistance of their restorations.

While according to this study the screw access channel has no influence on lithium disilicate groups, as there was no significant difference between both group A and group B, as the screw access hole was performed during milling of the restoration in the "blue state" where Lithium metasilicate crystals are precipitated with approximately $40 \%$ embedded in a glassy phase, this precrystallized blocks exhibit a flexural strength of 130 to $150 \mathrm{Mpa}$, which allows simplified machining, thus the screw access hole has no effect on the fracture resistance of lithium disilicate restorations.

\section{II-Fractographic analysis}

After loading of all the specimens till it reaches to catastrophic failure, it was noted that the cracks initiated at the restoration areas where the core materials were thinnest, also consistent with higher stress states.[29]

Prior studies have shown that the ability of all-ceramic restorations to withstand occlusal forces can be compromised by the presence of two types of inherent flaws within the restoration: the first was the internal defects like internal voids, porosities, or micro-structural features from fabrication and the other was the surface cracks and structural irregularities which are defects on the surface that result from machining and grinding. Fracture can begin from microscopic damage resulting and the interaction of preexisting defects with applied loads. Failure can also occur because of impact forces or subcritical crack growth, which can be enhanced in an aqueous environment.[30]

Most of the crowns from the lithium disilicate groups showed surface damage at the indenter site with cone cracks beneath the surface damage This was characteristic of glassy structures.[31]

In group $\mathrm{A}$ and group $\mathrm{B}$, all the directions of the crack propagation starts from the occlusal loading point then spread in a cone like shape directed toward the mesial or distal surface of the restoration away from the fitting surface or the screw access channel which may be contributed to that the milling of that restorations was performed in the blue state where the blocks didn't reach to its full hardness with its flexural strength of 130 to $150 \mathrm{Mpa}$ and the crystals of lithium metasilicate still embedded only $40 \%$ embedded in a glassy phase, upon crystallization of the restoration , the metasilicate crystal phase dissolved completely, and the lithium disilicate crystallizes where The microstructure consists of approximately $70 \%$ fine grain lithium disilicate crystals embedded in glassy matrixand results in a glass ceramic with fine grain size of approximately $1.5 \mathrm{~mm}$, which means that the glassy martix which is the weakest part in the block of the lithium disilicate ceramic which the cracks could be initiated will decrease in size upon crystallization and this place will be occupied by the lithium disilicate crystals where cracks upon milling could occur, and disappears and filled either during crystallization or glazing process.

This idea could be confirmed by the fractographic analysis of groupA and group B as the direction of the crack starts from occusal loading point then spread to cervical region and the peripheries of the restorations, away from the fitting surface and the screw access channel.

On the other hand, the restorations of group C and group D constructed from zirconium oxide ceramics, This material is polycrystalline solids, which has no glassy components and all the atoms are packed into a regular pattern making it dense and regular, all the cracks starts from the occlusal loading point which was distinguishable by the mirror then hackles along the axial wall of the fitting surface or related to the screw access channel, as the cracks mainly propagates in the weakest points and areas of the restoration, while sintering shrinkage occur, this disrupts the structural continuity of the zirconia crowns where the shrinkage occur toward the center of the mass of the ceramic bulk , so the cutting in the fitting surface disrupt the continuity of the zircon polycrystals and it becomes the weakest point in the group $\mathrm{C}$, so the direction of the crack propagation was along the axial wall of the fitting surface, while in group D when the screw access hole performed in the crowns, it disrupts thestructural continuity of the zirconia crowns at the occlusal surface, making this point is the weakest point in the restoration leading to the direct relation of the screw access channel with the cracks and the direction of the crack propagation which leads to catastrophic failure. 


\section{International Journal of Science and Research (IJSR) \\ ISSN (Online): 2319-7064}

Index Copernicus Value (2013): 6.14 | Impact Factor (2015): 6.391

\section{Conclusion}

With the limitations and Based on the findings of this in vitro study, the following was concluded:

1) According to lithium disilicate glass ceramics, No significant differences were found in fracture resistance between ceramic crowns with and those without screwaccess channels

2) Screw access channels significantly affect the fracture resistance of zirconium oxide ceramic crowns.

3) Ceramic crown design and material affect the fracture resistance, as monolithic zirconia implant-supported crowns showed significantly higher fracture resistance than monolithic lithium disilicate glass ceramics

\section{References}

[1] Palmer R, Howe L.Dental implants. 3. Assessment of the dentition and treatment options for the replacement of missing teeth. Br Dent J. 1999 11; 187:247-55.

[2] Tiossi R, Lin L, Conrad HJ, Rodrigues RC, Heo YC, de MattosMda G, Fok AS, RibeiroRF. Digitalimage correlation analysis on the influence of crownmaterial in implant-supportedprostheses on bonestraindistribution. J Prosthodont Res 2012; 56:25-31.

[3] Stegaroiu R, Kusakari H, Nishiyama S, Miyakawa O. Influence of prosthesismaterial on stressdistribution in bone and implant: a 3-dimensionalfinite element analysis. Int J Oral MaxillofacImplants 1998; 13:78190.

[4] Ismail Y, Kukunas S, Pipko D, Ibiary W. Comparative study of various occlusal materials for implant prosthodontics. J Dent Res. 1989; 68:962.

[5] Silva GC, Cornacchia TM, De Magalhães CS, Bueno AC, Moreira AN. Biomechanical Evaluation of Screwand Cement-Retained Implant-Supported Prostheses: A nonlinear Finite Element Analysis. J Prosthet Dent 2014; 112: 1479-88.

[6] Binon PP. The Effect of Implant/Abutment Hexagonal Misfit on Screw Joint Stability.Int J Prosthodont 1996; 9: $149-60$.

[7] De Carvalho W, Barboza P, CaúlaA. Cement-Retained Prostheses in Implant Dentistry: A Clinical Report. J Prosthet Dent 2001; 85: 345-8

[8] Gapski R, Neugeboren N, Pomeranz AZ, Reissner MW. Endosseous Implant Failure Influenced by Crown Cementation: A Clinical Case Report. Int J Oral Maxillofac Implants 2008; 23: 943-6.

[9] Manawar A, Dhanasekar B, Aparna IN, Naim H. Factors Influencing Success of Cement Versus ScrewRetained Implant Restorations: A Clinical Review. J Osseointegr 2012; 3: 43-7.

[10] Sailer I, MühlemannS,Zwahlen M, HämmerleCH, Schneider D. Cemented and Screw-Retained Implant Reconstructions: a Systematic Review of the Survival and Complication Rates. Clin Oral Implants Res 2012; 23:163-201.

[11] Kang HW, Lee DH. Using a Guide Template with a Hand piece Sleeve to Locate the Abutment Screw Position of a Cement-Retained Implant Restoration. J Prosthet Dent 2015; 114: 339-42.
[12] Gervais MJ, Wilson PR. A rationale for retrievability of fixed, implant-supported prostheses: a complicationbased analysis. Int J Prosthodont 2007; 20:13-24.

[13] Gultekin P, Gultekin BA, Aydin M, Yalcin S. Cement selection for implant-supported crowns fabricated with different luting space settings. J Prosthodont 2013; 22(2):112-9.

[14] Schweitzer DM, Berg RW, Mancia GO.A technique for retrieval of cement-retained implant-supported prostheses.J Prosthet Dent 2011; 106:134-8.

[15] Daher T, Morgano SM. The Use of Digital Photographs to Locate Implant Abutment Screws for ImplantSupported Cement-Retained Restorations.J Prosthet Dent 2008; 100: 238-9.

[16] Patil PG. A Technique for Repairing a Loosening Abutment Screw for a Cement-Retained Implant Prosthesis. J Prosthodont 2011; 20: 652-5.

[17] Wadhwani C, Chung KH. Simple Device for Locating the Abutment Screw Position of a Cement-retained Implant Restoration.J Prosthet Dent 2013; 109: 272-4.

[18] Rajan M, Gunaseelan R. Fabrication of a cement- and screw-retained implant prosthesis. J Prosthet Dent 2004; 92:578-80.

[19] Tosches NA, Brägger U, Lang NP. Marginal Fit ofCemented and Screw-Retained Crowns Incorporated on the Straumann (ITI) Dental Implant System: An in Vitro Study. Clin Oral Implants Res 2009; 20: 79-86.

[20] Al-Omari WM, Shadid R, Abu-Naba'a L, El Masoud B. PorcelainFractureResistance of Screw-Retained, Cement-Retained, and Screw-Cement-RetainedImplantSupportedMetalCeramicPosteriorCrowns. J Prosthodont 2010; 19: 263-73.

[21] Shadid RM, Abu-Naba'a L, Al-Omari WM, Asfar KR, El Masoud BM. Effect of an Occlusal Screw-Access Hole on the Fracture Resistance of Permanently Cemented Implant Crowns: A Laboratory Study. Int J Prosthodont 2011; 24: 267-9

[22] Kelly JR. Dental ceramics: Current Thinking and Trends. Dent Clin NorthAm 2004; 48: 513-30.

[23] Li R, Chow T, Matinlinna J. Ceramic dental biomaterials and CAD/CAM technology: state of the art.J Prosthodont Res 2014; 58: 208-16.

[24] McGlumphy EA, Papazoglou E, Riley RL. The combination implant crown: acement and screw retained restoration. CompendContinEducDent1992; $13: 34-41$.

[25] Torrado E, Ercoli C, Al Mardini M, Graser GN, Tallents RH, Cordaro L. A Comparison of the Porcelain Fracture Resistance of Screw-Retained and Cement-Retained Implant-Supported Metal-Ceramic Crowns. J Prosthet Dent 2004; 91: 532-7.

[26] Zarone F, Sorrentino R, Traini T, Di lorio D, Caputi S. Fractureresistance of implant-supportedscrewversuscement-retainedporcelainfused

to metalsinglecrowns: SEM fractographic analysis. Dent Mater 2007; 23: 296-301.

[27] Karl M, Graef F, Taylor TD, Heckmann SM .In vitro effect of load cycling on metal-ceramic cement- and screw-retained implant restorations. J Prosthet Dent 2007; 97:137-40. 


\section{International Journal of Science and Research (IJSR) \\ ISSN (Online): 2319-7064}

Index Copernicus Value (2013): 6.14 | Impact Factor (2015): 6.391

[28] Parle D, Desai D, Bansal A. Esttimation of Individual Bite Force during Normal Occlusion using FEA. India: Altair Technology Conference; 2013: 1-9.

[29] Quinn JB, Quinn GD, Kelly JR, Scherrer SS. Fractographic Analyses of three Ceramic Whole Crown Restoration Failures. Dent Mater 2005; 21: 920-9.

[30]Zahran M, El-Mowafy O, Tam L, Watson PA, Finer Y. Fracturestrength and fatigueresistance of allceramicmolarcrownsmanufactured with CAD/CAMtechnology. J Prosthodont 2008; 17: 370-7.

[31]Lawn BR, Deng Y, Thompson VP. Use of contacttesting in the characterization and design of allceramic crown like layer structures: a review. J Prosthet Dent 2001; 86: 495-510.

\section{Author Profile}

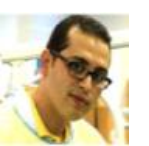

Amr El-Sayed Khalifa, received the B.D.S. in Dental and Oral Surgery from Alexandria University, faculty of dentistry 2006. During 2006-2007, he practiced in Ministry of Health. During 2008-2009, he serviced in Egyptian military force. Since 2010 till now, he is one of the staff in Removable prosthodontic Department faculty of dentistry. Pharos University Alexandria, Egypt. During 2011-2016, he educated for M.S degree in prosthodontics in prosthetic department, faculty of dentistry. Alexandria University

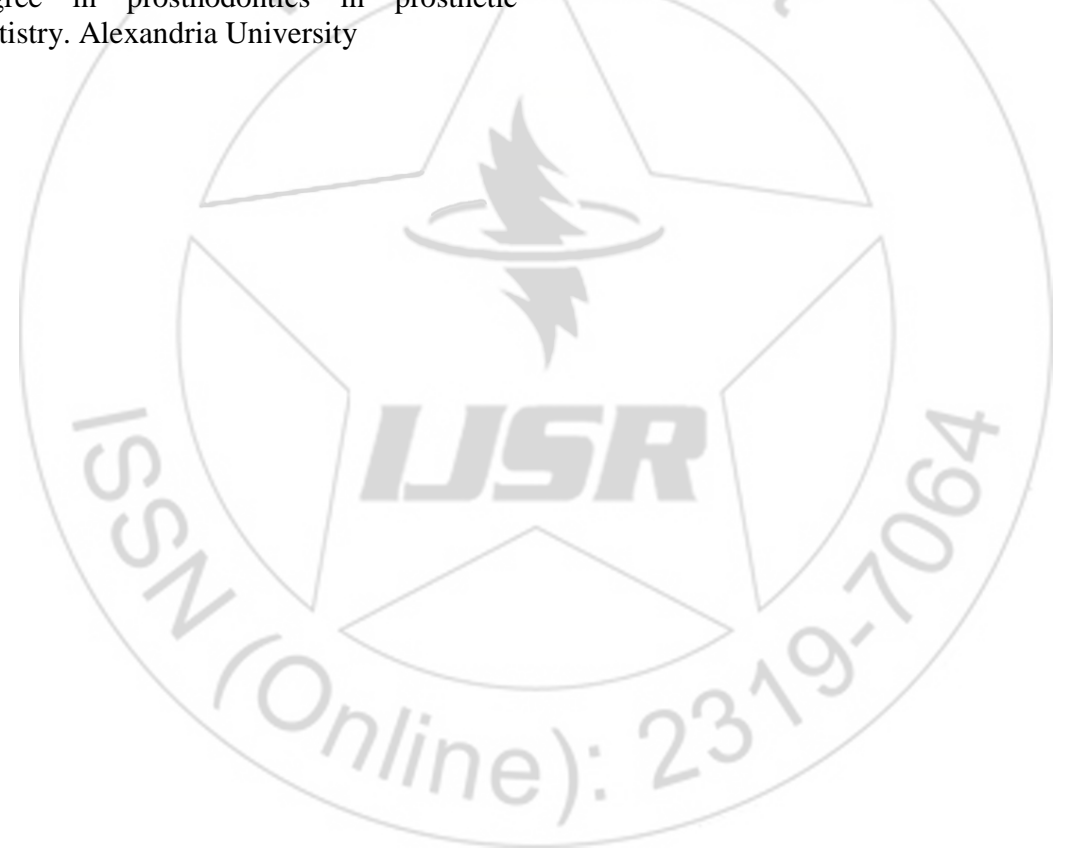

